\title{
Fecundidade e tipo de desova do tamuatá, Hoplosternum littorale Hancock (Osteichthyes, Siluriformes) no Rio Curiaú, Macapá, Amapá
}

\author{
Júlio César Sá-Oliveira ${ }^{1}$ \\ Sathyabama Chellappa ${ }^{2}$
}

\begin{abstract}
Fecundity and type of spawning of tamuatá, Hoplosternum littorale Hancock (Osteichthyes, Siluriformes) in Curiaú River, Macapá, Amampá. During June 1999 to June 2000 one hundred and forty seven females of Hoplosternum littorale Hancock, 1828 were collected from the Curiaú River, Macapá, Amapá, Brazil. The objective of this study was to determine the fecundity and the type of spawning of $H$. littorale. Analysis of the percentage distribution of the oocyte diameters of the females, in five different stages of gonadal development, showed that this species is a total spawner. There were two different size groups of oocytes with synchronic development. The total fecundity varied from 9,144 to 31,698 mature oocytes. The fecundity, when related to total length and weight, showed that it increases with the enhance in total length and weight.

KEY WORDS. Osteichthyes, Siluriformes, Hoplosternum littorale, fecundity, type of spawning
\end{abstract}

A fecundidade é um dos aspectos mais importantes a ser considerado na biologia reprodutiva. Entretanto, ela é raramente contemplada nos estudos de biologia e ecologia dos peixes amazônicos (FERREIRA \& SANTOS 1999). A fecundidade é ainda um dos parâmetros mais importante para o estudo da biologia pesqueira, já que a intensidade anual do recrutamento depende tanto da quantidade de fêmeas "desovantes" como da fecundidade individual dessas fêmeas (CSIRKE 1980).

O tipo de desova nos peixes é determinado pela interação entre a dinâmica do desenvolvimento ovocitário, a freqüência de desovas dentro de um período de reprodução e o número desses períodos durante sua vida (VAZZOLER 1996). Este tipo de informação é importante, pois demonstra a capacidade de adaptação das espécies às flutuações ambientais.

O tamuatá, Hoplosternum littorale Hancock, 1828 é uma das espécies ícticas mais apreciadas para o consumo pela população amapaense e apresenta-se de forma marcante no sistema rio-planície de inundação da Área de Proteção Ambiental (APA) do Rio Curiaú, Amapá. Além do mais, este peixe vem se destacando como item de exportação, comercializado principalmente com a França e EUA. O presente estudo teve como objetivo conhecer a fecundidade e tipo de desova de $H$. littorale

1) Departamento de Biologia, Universidade Federal do Amapá. Rodovia JK, Km 02, 68900-000 Macapá, Amapá, Brasil. E-mail: juliosa@unifap.br

2) Programa de Pós-Graduação em Bioecologia Aquática, Departamento de Oceanografia e Limnologia, Centro de Biociências, Universidade Federal do Rio Grande do Norte. Praia de Mãe Luiza, 59014-100, Natal, Rio Grande do Norte, Brasil. E-mail: bama@ dol.ufrn.br 
que contribuirá para melhor compreensão da fisioecologia do tamuatá, gerando insumos para proposições de medidas de corretas estipulação de normas de manejo dos seus estoques naturais.

\section{MATERIAL E MÉTODOS}

A Área de Proteção Ambiental (APA) do Rio Curiaú localiza-se no Município de Macapá, Amapá região Norte do Brasil e ocupa uma área de extensão de 23.000 ha. Está delimitada pelas coordenadas $00^{\circ} 14^{\prime} 58^{\prime \prime}-00^{\circ} 14^{\prime} 17^{\prime \prime} \mathrm{N}$ e $50^{\circ} 56^{\prime} 54^{\prime \prime}$ $51^{\circ} 07^{\prime} 46^{\prime \prime} \mathrm{W}$. O cenário físico natural predominante é caracterizado pelo domínio da bacia do rio Curiaú e de seus ambientes de entorno, formados de importantes ecossistemas florestais como cerrado, floresta tropical úmida e ecossistemas aquáticos como lagos temporários e lagos permanentes. Apesar de constituir uma área de proteção ambiental, vem sofrendo grandes modificações antrópicas como urbanização e construção de estradas que causam impactos ambientais ainda não mensurados neste ambiente.

Duzentos e vinte e dois indivíduos de $H$. littorale, dos quais 147 eram fêmeas foram coletados em um total de seis coletas durante o período de seca (julho à dezembro de 1999) e durante o período de cheia (janeiro a maio de 2000). Os petrechos de pesca foram cinco redes de espera, sendo três com dimensões: $15 \mathrm{~m} \mathrm{x}$ $1,5 \mathrm{~m}$ de malha $30 \mathrm{~mm}$ entre nós opostos e fio 30; um com dimensões: $15 \mathrm{~m} \times 1,5$ $\mathrm{m}$ de malha $20 \mathrm{~mm}$ e fio $30 \mathrm{e}$ um com dimensões de $15 \mathrm{~m} \mathrm{x} 1,5 \mathrm{~m}$ de malha $40 \mathrm{~mm}$ e fio 30, nos ecossistemas lênticos (lago permanente e lago temporário) e lótico (rio Curiaú) da APA do Rio Curiaú. Todos os peixes foram numerados, pesados, medidos seu comprimento total, comprimento padrão e altura do corpo. Suas gônadas foram observadas e retiradas para pesagem e fixação.

A fecundidade e o tipo de desova foram determinados segundo metodologia proposta por VAZZOLER (1996), com base na contagem absoluta dos ovócitos vitelogênicos e na determinação de classes de diâmetro dos ovócitos. Especificamente para o estudo do tipo de desova, os ovários em diferentes fases de desenvolvimento foram preservados em solução de Gilson modificada (SIMPSON 1951), por vinte e quatro horas, objetivando a dissociação completa dos ovócitos. Posteriormente, os ovócitos foram lavados em álcool a $70^{\circ} \mathrm{GL}$. Cada amostra foi transferida para um balão volumétrico, com o seu volume aumentado para $250 \mathrm{ml} \mathrm{com} \mathrm{álcool} \mathrm{a} 70^{\circ} \mathrm{GL}$. Após a homogeneização do material, retiraram-se, com auxílio de uma pipeta graduada, duas subamostras de $2 \mathrm{ml}$. Os ovócitos destas amostras foram medidos sob estereoscópio Wild M7 (objetiva 31x; ocular 10x). Após isso, o tipo de desova foi avaliado através da análise do diâmetro dos ovócitos $(\mathrm{em} \mu \mathrm{m})$ e suas frequiências relativas, por classes de diâmetro de $500 \mu \mathrm{m}$. Os dados foram lançados em forma de gráficos e interpretados para esclarecer o tipo de desova (VAZZOLER 1996).

Para determinar a fecundidade, quinze gônadas de fêmeas de $H$. littorale, (desde os menores até os maiores exemplares maduros), foram pesadas e dissociadas em solução de Gilson. Com um pincel, foram retirados as membranas e restos de tecidos. Em seguida, sob um estereoscópio, contou-se os ovócitos vitelogênicos contidos em cada gônada e posteriormente calculou-se a média. Para o cálculo da fecundidade foram considerados todos os ovócitos a partir de $500 \mu \mathrm{m}$. 
A média da fecundidade absoluta, comprimento total (Lt) e peso da gônada (Wg) foram relacionadas, além do cálculo do RGS (relação gonadossomática), que é a razão entre o peso dos ovários e o peso eviscerado do peixe x 100 (VAZZOLER 1996).

\section{RESULTADOS E DISCUSSÃO}

Os valores mínimos e máximos da fecundidade de $H$. littorale na APA do Rio Curiaú, foram 9.144 e 31.698 ovócitos maduros de um total de quinze fêmeas escolhidas desde os menores até os maiores exemplares maduros. A média da fecundidade absoluta para a espécie foi de 17.096,3 ovócitos com diâmetro acima de $1.000 \mu \mathrm{m}$. A relação entre a fecundidade e comprimento total foi do tipo exponencial e entre a fecundidade e comprimento total foi do tipo linear sendo essas relações significativas no nível de 5\%. As relações entre a fecundidade absoluta e comprimento total e entre a fecundidade absoluta e peso das gônadas para fêmeas de $H$. littorale, demonstram que a fecundidade aumenta com o incremento do comprimento total e peso das gônadas (Fig. 1).
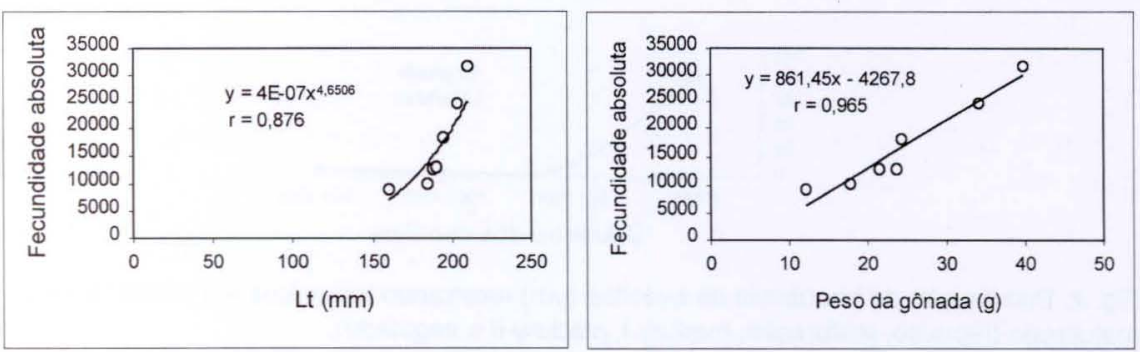

Fig. 1. Relação entre a fecundidade absoluta e o comprimento total e o peso das gônadas em fêmeas de $H$. littorale.

Nos peixes, existem além das outras células germinativas em desenvolvimento, uma fonte renovável e contínua de ovócitos a partir do epitélio folicular, o que explicaria o incremento nos valores absolutos da fecundidade com o crescimento. Assim a cada desova um número maior de células permanece nos ovários aumentando o estoque de ovócitos neoformados (VAZZOLER 1996).

A distribuição da freqüência relativa do diâmetro dos ovócitos por classe de diâmetro com intervalos de 500 micra (apresentada na figura 2), revela um desenvolvimento ovocitário sincrônico em dois grupos: o de ovócitos do estoque de reserva, com diâmetros menores que 500 micra observado durante o bimestre agosto-setembro que evolui para as fases III e IV em outubro-novembro e para a fase V no bimestre dezembro-janeiro. Esses resultados indicam que o tipo de desova é anual total.

Em relação aos valores médios de RGS por estádio de desenvolvimento gonadal, foram observados os seguintes: No estádio em repouso, onde a gônada apresentou maior número de ovócitos menores com diâmetro inferior a $500 \mu \mathrm{m}$ o RGS foi de 1,66. No estádio de maturação, onde a gônada apresentou maior quantidade de ovócitos com diâmetros inferiores a $1000 \mu \mathrm{m}$ e superiores a $500 \mu \mathrm{m}$ 

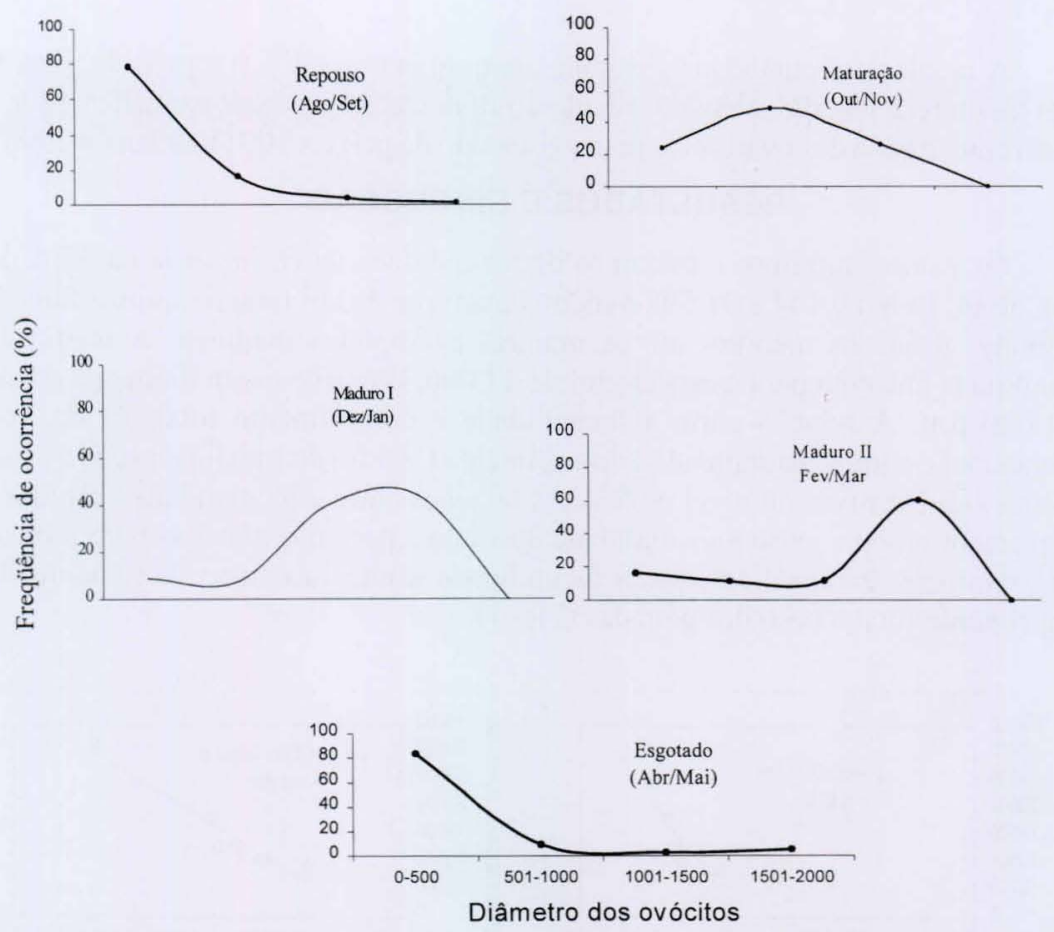

Fig. 2. Distribuição de freqüência de ovócitos $(\mu \mathrm{m})$ mostrando individuos em várias fases de maturação (repouso, maturação, maduro I, maduro II e esgotado).

o RGS foi de 2,97. Durante o estádio maduro I, onde os ovócitos apresentaram-se em maior número com diâmetros superiores a $1500 \mu \mathrm{m}$, o RGS foi o maior, atingindo um valor de 14,8. Após, no estádio maduro II o RGS diminuiu devido ao início da desova. O comportamento temporal do RGS obtendo nível máximo em dezembro para logo em seguida diminuir em fevereiro e praticamente tornar-se nulo em abril, deveu-se a maturação e desova de $H$. littorale.

\section{CONCLUSÃO}

A fecundidade de Hoplosternum littorale do Rio Curiaú é baixa com grande variação e apresenta relação com o comprimento total e peso das gônadas. O tipo de desova é sincrônico em dois grupos caracterizando tipo de desova total.

\section{REFERÊNCIAS BIBLIOGRÁFICAS}

CSIRKE, J. 1980. Introducción a la dinámica de poblaciones de peces. Doc. Pesca, FAO, (192): 1-82. Ferreira, E.J.G. \& G.M..SAntos. 1999. Peixes da Bacia Amazônica. In: R.H. Lowe-McConnell (Ed).

Estudos Ecológicos de Comunidades de Peixes Tropicais. São Paulo, EDUSP, 344p. SimpSon, A.C. 1951. The fecundity of the plaice. Fish. Invest., London, (2) 17 (5): 1-27. VAzzoler, A.E.A.M. 1996. Biologia de reprodução de peixes Teleósteos: Teoria e Prática. Maringá, EDUEM, $169 \mathrm{p}$. 